\title{
Empathy and Autonomic and Hemodynamic Cardiac Responses
}

\author{
Leonardo Rodrigues Sampaio* (D, Alfredo Anderson Teixeira-Araújo (D), \\ Glaycianny Pires Alves Lira (D, \& Sérgio Rodrigues Moreira (D) \\ Universidade Federal do Vale do São Francisco (UNIVASF), Petrolina, PE, Brasil
}

\begin{abstract}
Hemodynamic and autonomic responses have been used as sensitive indicators of cardiovascular health in situations involving emotions. However, few studies evaluated these indicators when feelings result from vicarious experiences. This research aimed to verify if empathy measures would be associated with variations in blood pressure, heart rate, rate pressure product, and heart rate variability in young adults, after exposure to experimental situations. Results point out that hemodynamic and autonomic cardiac indicators were associated with dispositional and situational empathy. These results are discussed based on Martin Hoffman's theory and in the light of recent findings in the field of Psychophysiology.
\end{abstract}

KEYWORDS: empathy, cardiovascular system, tv report, self-report

\section{Empatia e Respostas Hemodinâmicas e Autonômicas Cardíacas}

\begin{abstract}
RESUMO - Respostas hemodinâmicas e autonômicas têm sido utilizadas como indicadores sensíveis da saúde cardiovascular durante situações de cunho emocional. Todavia, ainda são escassos os trabalhos que avaliam esses indicadores quando os sentimentos produzidos ocorrem a partir de experiências vicárias. O presente estudo objetivou verificar se medidas de empatia estariam associadas a variações nos indicadores de pressão arterial, frequência cardíaca, duplo produto e variabilidade da frequência cardíaca em jovens adultos, após sua exposição a situações-estímulo. Os resultados indicam que indicadores hemodinâmicos e autonômicos cardíacos estiveram associados a componentes da empatia situacional e da empatia constitucional. Estes resultados são discutidos com base na teoria de Martin Hoffman e a partir de achados recentes no campo da Psicofisiologia.
\end{abstract}

PALAVRAS-CHAVE: empatia, sistema cardiovascular, reportagem, autorrelato

Studies with physiological measures are quite traditional in Psychological Sciences (Rainville, Bechara, Naqvi, \& Damasio, 2006; Sinha, Lovallo, \& Parsons, 1992). Over the years, these studies produced evidence that point out to the existence of relationships between specific standards of cardiac autonomic activity and basic emotions such as anger, sadness, happiness, disgust, fear and surprise (Ekman, Leverson, \& Freiser, 1983; Prkachin, WilliamsAvery, Zwaal, \& Mills, 1999). In the investigation of the autonomous nervous system (ANS) activity, cardiac hemodynamic responses and heart rate variability (HRV) indicators are largely used to assess the cardiovascular health, and show sound sensitivity to situational clues of emotional nature, even when variations are not consciously detectable (Freydefont, Gendolla, \& Silvestrini, 2012; Gendolla, 2012).
A recent study, for example, showed that the diastolic blood pressure (BP) of alexithymic and unassertive individuals significantly increased when they were asked to express emotions (Lipp, Pereira, Justo, \& De Matos, 2006). In assertive and non-alexithymic individuals, in turn, the systolic BP showed significant increases when they were asked to inhibit their emotions. In this same line, James, Yee, Harshfield, Blank and Pickering (1986) observed that emotional excitement significantly increases the systolic and diastolic BP, regardless of the place where the individual is, and that in the states of anger and anxiety both BPs increased more than when individuals said to be happy.

On the other hand, emotional responses that generate a conservation-escape standard of the organism, such as sadness, are characterized by high parasympathetic activity and consequent dampening of heart rate (HR), in addition to

*E-mail: leorsampaio@yahoo.com.br

- Submetido: 18/01/2017; Revisado: 19/09/2017; Aceito: 25/09/2017. 
the constriction of upper airways associated to a moderate sympathetic co-activation that shortens the preejection period and raises the SBP (Kreibig, Wilhelm, Roth, \& Gross, 2007).

Another qualitative cardiovascular health parameter also important which can be changed by emotional experiences is the HRV. This can be observed from the oscillation of intervals between consecutive heart beats (R-R intervals) on the electrocardiogram that indicates the ANS modulation over time (Task Force of The European Society of Cardiology and The North American Society of Pacing and Electrophysiology, 1996).

The HRV is largely used to assess the sympathovagal dynamic of individuals in different population groups and environmental contexts (Tulppo, Mäkikallio, Seppänen, Airaksinen, \& Huikuri, 1998). Moreover, the HRV is adopted to diagnose physiological and psychological disorders and to assess the influence of different environmental conditions and mental stress (Pinna et al., 2007; Ewing, Neilson, Shapiro, Stewart, \& Reid, 1991). Changes on the standards of the HRV offer a sensitive and anticipated indicator of damages to the cardiovascular health. The HRV dampening ( $\mathrm{R}-\mathrm{R}$ intervals) is associated to high rate of mortality. However, little is known about the BP and HRV responses associated to psychological measures derived from different emotional states. This suggests the need for new studies adopting this approach.

In this regard, Oliveira-Gonçalves and Gonçalves (2011) state that despite the relative multitude of research on the neurobiological mechanisms that enable the understanding about the others' emotions, few studies explore the role of these mechanisms in the emotional responses of vicarious origin, such as empathy. In their study, the authors observed that empathetic responses of individuals were associated to the cardiovascular activity, but not to variations on the skin conductivity. This would suggest that the first variable would be a kind of physiological marker more sensitive to empathy than the latter.

Looking into these results, Oliveira-Silva and Gonçalves (2011) raised the possibility that maybe the stimulus situations used by them was not intensive enough to activate the neurobiological mechanisms associated to empathy, as they refer to short vignettes (around 25 seconds) during which the players expressed different types of emotions. Therefore, it would be interesting to question if the use of situational clues (stimuli) more emotionally intense and closer to the participants' reality would have generated physiological excitement patterns different from those observed by Oliveira-Silva and Gonçalves.

Preston and De Waal (2002) consider the ability of empathizing with others was one of the primary facts to the organization of social species because it allowed similar organisms to share emotional states with their peers, by activating autonomous somato-physiological mechanisms.
According to Hoffman (2000) the reflex and automatic vicarious emotional responses would be present since a baby is born, and would be a more primitive aspect of the affective-communicational capacity of the human being that is improved as they mature.

In general, empathy could be analyzed from its constitutional components (empathy "trace" or "dispositional") and situational (empathy state) (Sampaio, Moura, Guimarães, Santana, \& Camino, 2013). While the constitutional empathy refers to permanent and long-lasting aspects of the personality developed on ontogenesis, the situational empathy concerns the emotional responses temporarily produced, as a result of the type and intensity of the emotional stimuli to which the individual is subjected.

The use of somatic and physiological indexes to assess the situational empathy lessens the potential negative effects of the social desirability on the responses of the research participants, so usual when self-report measures are used (Eisenberg, Fabes, Bustamantes, \& Mathy, 1987). On the other hand, it is a drawback as it only indicates general excitement patterns, not differentiating the quality of the individuals' affective experiences. In this sense, the combined use of different types of instruments has a methodological advantage over the strategies traditionally applied to the study of empathy. In this regard, the study by Fuskushima, Terasawa and Umeda (2011) indicated relationships between measures of empathy self-report and amplitude values of $\mathrm{HR}$.

As aforementioned, a great deal of the cited studies tried to assess the ANS activity when individuals were subjected to self-referenced emotions, or tested the degree of autonomous activation in face of emotional stimuli out of context, such as words or facial expressions. The present study tried to assess the cardiovascular modulation in situations where emotional responses were vicariously produced, i.e., when the individual witnessed somebody's else suffering, misfortune or anguish. The study was based on Hoffman's (2000) definition that empathy is understood as an emotional response more suitable to the other's situation than to the observer's situation. In other words, empathy is a kind of response that produces emotional echo on a person that just observes or imagines the other's situation, making the observer experience affections only expected in someone really experiencing the situation of misfortune.

Therefore, it would be reasonable to assume that the vicarious experience caused by empathy is congruent with the cardiovascular responses produced by the affections felt by the observer when this observer is the directly involved with situations of emotional content. Thus, it is expected that these physiological responses can be measured and detected. Given the above, the main objective of this study was to assess if there is any relation between empathic feelings and the standards of hemodynamic and autonomic cardiovascular activity in young adults, resulting from the exposure to 
ordinary stimulus situations of affective content. Based on previous study (Sampaio et al. 2013) stimuli were used that induced individuals to feel empathy for the main player of news aired on the Brazilian open TV. In two of these news the main players were presented as potential victims what, according to Hoffman (2000) is a factor that predisposes people to feel empathy one for another, while the other two news were considered empathically "neutral" and served as parameter of comparison between the cardiovascular responses and self-related empathic responses.

\section{METHOD}

\section{Sample}

The sample consisted of 21 university students (nine men and twelve women), with ages ranging from 18 to 25 years $(\mathrm{M}=21.57 \pm 1.96$ years $)$, physically active and recruited in a public university in the city of Petrolina, Pernambuco, Brazil. The sample was non probabilistic as only individuals fitting into the inclusion profile and willing to volunteer to the study have participated.

Following were the criteria of inclusion in the sample: be healthy (health status established based on the anamneses with assessment of signs and symptoms suggestive of cardiopulmonary disease), BP in rest lower than $130 \times 85$ $\mathrm{mmHg}$ to the systolic and diastolic BP, respectively, and have no family or personal history of cardiovascular disease. The exclusion criteria, in turn, were: history of mental disease, be smoker or obese (assessed by the body mass index - BMI), continuous use of medications that could interfere on the cognitive or cardiovascular function such as: beta-blockers (e.g., propranolol, atenolol), diuretic (e.g., furosemide, hydrochlorothiazide), calcium channel blockers (e.g., nifedipine, amlodipine) and of the angiotensin converting enzyme (e.g., captopril, enalapril).

\section{Instruments and Materials}

The HR and R-R intervals (RRi) of the HRV were recorded using a frequency meter brand Polar $\AA$, model RS800CX, which is a validated equipment with high reproducibility (Willians et al., 2016). In the beginning of the experimental sessions the electrode of the frequency band of the frequency meter was damped with gel to facilitate the electro-physiological signal conduction. Then, the signal generator was fixed to the frequency band that was placed around the chest, tight and in contact with the volunteer's skin (at the level of the xiphoid process of sternum). After checking the signal on the pulse monitor, the absolute record of the HRV RRi was started and continued until the end of the experimental session.

The HRV RRi records were exported, by infrared, from the frequency meter to the Polar ProTrainer 5 software and analyzed using the software Kubios HRV, version 2.0. To avoid damages to the reliability of the indexes found, all artifacts were removed and the premature and ectopic beats corrected, based on the criterion of difference higher than $20 \%$ in relation to the adjacent beats. After editing the RRi in 5-minute periods, the domains of time and frequency were subjected to analyses with the linear methods to estimate the indicators of the sympathetic and parasympathetic nervous system. In the domain of time, the mean RRi (ms) was the parameter analyzed; in the domain of frequency the analysis comprised the components of high frequency (HF 0.15 to $0.4 \mathrm{~Hz}$ ), low frequency (LF $0,04 \mathrm{e} 0,15 \mathrm{~Hz}$ ) and the $\mathrm{LF} / \mathrm{HF}$ ratio, characterizing the sympathovagal balance on the heart (Task Force of The European Society of Cardiology, 1996).

The BP was measured using an automatic sphygmomanometer, brand Microlife, model BP3AC1-1PC. The equipment is validated and with high reproducibility in normotensive individuals (Topouchian, Assaad, Orobinskaia, Feghali \& Asmar, 2005). The procedures adopted to assess the BP were those recommended by the Brazilian Society of Cardiology (SBC, 2010): the cuff was tightly placed 2 to $3 \mathrm{~cm}$ above the cubital fossa, centralizing the center of the compressive piece on the brachial artery. Volunteers were comfortably set down, with the upper left limb relaxed at the heart level (approximately on the fourth intercostal space). Moreover, the Rate Product Pressure (RPP), variable that expresses the absolute rate of overload on the myocardium was also estimated based on the multiplication of systolic $\mathrm{BP}$ and the HR. During the measures of BP, HR and RRi the participant was asked to turn off the cell phone, not cross the legs, stay quiet and not talk until all the information collection procedures were completed.

Dispositional empathy was assessed using the Interpersonal Reactivity Index - IRI (Davis, 1983). This is a self-report instrument, pencil and paper type, used to measure four empathy dimensions: perspective-taking (cognitive capacity of taking on and understanding the other's point of view); fantasy (trend towards identifying and imagining the self in the place characters of a film, soap opera, and books); empathic concern (motivation that predisposes the individual to help other persons undergoing some kind of suffering, misfortune or injustice); and personal distress (feelings of nuisance, discomfort or uneasiness experienced in the self, when the person imagines or observes someone else's 
suffering). This study used the version with 26 IRI items, adapted and validated by Sampaio, Guimarães, Camino, Formiga and Menezes (2011).

Situational empathy, in turn, was assessed using a scale designed by Sampaio et al. (2013) that asks the degree of intensity of 10 different groups of feelings experienced after exposure to stimuli situations, on a scale ranging from 0 (I did not experience this feeling) to 5 (very strong).

Finally, four videos from an internet portal were used as experimental stimuli. Two videos were of emotional character, and two were neutral. News presented the following situations: I. A mom forgets her baby in the car and the baby ends up by dying; II. Hidden camera catches a nanny beating a child with Down's syndrome; III. Discovery of water in the moon; IV. Discovery of a dinosaur fossil by Brazilian researchers. The two first ones are of emotional character and aimed at stimulating the experience of empathic feelings among participants, as previously demonstrated in the study carried out by Sampaio et al (2013). The last two, in turn, were of a more "neutral" character and with low possibility of activating empathic feelings, as topics were not necessarily connected to the feelings of another person, and did not describe events with some kind of potential victim (Hoffman, 2000).

\section{Data Collection Procedures}

Participants were invited to come to the Univasf Development-Learning and Psychosocial Processes Lab (LDAPP) to participate in the study. First, they answered questionnaires about their life history and health habits (anamneses). Then, participants underwent an anthropometric assessment (stature, weight, body mass index and waist circumference) (Lohman, Roche, \& Martorell, 1988) and fat percentage (Jackson \& Pollock, 1978; Jackson, Pollock, \& Ward, 1980), besides the measures of BP, HR and HRV.

Following, participants were informed about the overall procedures and objectives of the study, and data collection was scheduled. The experimental sessions took place no later than three days after the first contact, and participants were asked to avoid physical exercises, and the ingestion of food and beverage with caffeine or alcohol for 24 hours prior to the experiment. Complying with the predefined schedule, participants came to the LDAPP and, firstly, stayed a time in rest in a quiet and silent room, with controlled temperature and luminosity. While in rest, participants remained lying supine for 20 minutes (pre-experiment period) to measure BP, HR and HRV every 5 minutes, which allowed building the baseline for those measures.

In the next stage, participants watched the four aforementioned news (stimuli situations) that were displayed on a portable computer, notebook, with 14.5" screen. The video exhibition period started 5 minutes after the pre-experiment rest (Dantas et al., 2010). Before starting measuring the BP, HR and HRV, we ensured that participants' bladders were not full, that they had not practiced any exercise, had not ingested alcohol, coffee or food with any type of stimulant for at least 24 hours prior to the experimental session (Sociedade Brasileira de Cardiologia [SBC], 2010).

After watching each video, participants answered the situational empathy scale in the following format: "Now we would like you to assess the intensity of each of the of the following feelings that you might have experienced when you watched the news, using the following scale: $0=$ I had not this feeling when I watched the video; 1 = very weak; $2=$ weak; 3 = reasonable intensity; 4 = strong; 5 = very strong". After these instructions, ten different types of feeling (anger, sadness, compassion, injustice, anguish, guilt, contempt, shame, happiness, and pride were presented, following the same procedures adopted by Sampaio et al (2013).

During and immediately after the video exhibition, the BP, HR and HRV were continuously assessed. The videos exhibition sequence was randomized to avoid effects of order. As the last stage of data collection, participants were left alone in the room to answer the Davis' (1983) IRI.

All data collection procedures were made in a room with controlled temperature ranging from $23^{\circ} \mathrm{C}$ to $24^{\circ} \mathrm{C}$ (Dantas et al., 2010), with no sound or noise that could interfered on measures. Moreover, data were always collected in the afternoon shift (from $3 \mathrm{pm}$ to $4 \mathrm{pm}$ ), since cardiovascular modulation may suffer adjustment due to the circadian rhythm. For example, the levels of cortisol, a reliable indicator of stress, will always be high in the morning (Singh et al., 1998).

Before any procedure, the research was approved by the Committee of Ethics in Studies and Research of Univasf (registration no. 0015/220514 CEDEP/UNIVASF). All participants were informed about the objectives and methods adopted in the research. After approval and acceptance of the methodological procedures, participants were instructed to sign an Informed Consent Form (ICF) according to resolution 466/12 of the National Health Council. 


\section{RESULTS}

\section{Characteristics of the Sample}

Table 1 presents the anthropometric characterization of the sample investigated.

Table 1.

Anthropometric characterization of the sample, expressed as mean ( \pm sd)

\begin{tabular}{lccc}
\hline & $\begin{array}{c}\text { Total } \\
(\mathbf{n = 2 1})\end{array}$ & $\begin{array}{c}\text { Female } \\
(\mathbf{n = 1 2})\end{array}$ & $\begin{array}{c}\text { Male } \\
(\mathbf{n = 9 )}\end{array}$ \\
\hline Age (years) & $21,6 \pm 2,0$ & $21,5 \pm 2,2$ & $21,7 \pm 1,7$ \\
Weight (kg) & $68,0 \pm 18,1$ & $58,1 \pm 7,4$ & $81,3 \pm 19,9$ \\
Stature (cm) & $163,7 \pm 4,6$ & $157,8 \pm 4,6$ & $171,6 \pm 8,9$ \\
$\begin{array}{l}\text { Body Mass } \\
\left.\text { Index (kg.m }{ }^{-2}\right)\end{array}$ & $25,2 \pm 4,9$ & $23,4 \pm 3,4$ & $27,5 \pm 5,7$ \\
$\begin{array}{l}\text { Waist } \\
\text { circumference } \\
(\mathrm{cm})\end{array}$ & $76,1 \pm 13,0$ & $69,5 \pm 5,0$ & $84,9 \pm 15,3$ \\
Fat (\%) & $22,6 \pm 8,3$ & $26,5 \pm 4,4$ & $17,5 \pm 9,6$ \\
\hline
\end{tabular}

\section{Physiological Indicators of Heart Activity}

The measures of BP, HR and RRi of the HRV were used to assess the hemodynamic physiological indicators of the cardiovascular system. The BP corresponded to the stress of the blood on the vascular walls. The systolic BP (SBP), that represents the pressure by the time blood is pumped by the heart (systole or highest pressure in the artery), and the diastolic BP (DBP), that represents the moment when the heart relaxes after contraction (diastole or lowest pressure in the artery), were measured. The mean BP (MAP) was obtained from the following equation: $\mathrm{MAP}=\mathrm{DBP}+[0.333$ $\mathrm{x}$ (SBP - DBP)] (Kenney, Wilmore \& Costill, 2013). The heart rate (HR), which corresponds to the number of heart beats a minute, was also measured. Moreover, the RPP was calculated. The RPP represents the absolute overload of the myocardium, calculated through the following equation: RPP $=$ SBP x HR (Queiroz et al., 2013).

The autonomic cardiac indicators analyzed were on the linear method of time domain. That is, the average of the RRi records (mean of R-R intervals of consecutive heart beats) and on the spectral analysis-based frequency method, including low frequency (LF) in normalized units (HF n.u.) as a marker of vagal tone (parasympathetic) to further obtain the LF:HR ratio. This ratio represents the sympathovagal balance on the heart, reflecting the relative changes between the ANS sympathetic and parasympathetic components (Vanderlei, Pastre, Hoshi, Carvalho \& Godoy 2009).
Friedman's ANOVA showed significant difference among the following cardiovascular responses in relation to the videos displayed: $\operatorname{SBP}\left[\chi^{2}(3)=14.667, p<0.01\right]$, $\operatorname{DBP}\left[\chi^{2}(3)=9.829, p<0,05\right], \operatorname{MAP}\left[\chi^{2}(3)=8.385, p<\right.$ $0.05]$, HR $\left[\chi^{2}(3)=9.629, p<0.05\right], \operatorname{RPP}\left[\chi^{2}(3)=14.886, p\right.$ $<0.01]$ and LF:HR ratio $\left[\chi^{2}(3)=9.702, p<0.05\right]$ (Figures $1 \mathrm{~A}, 1 \mathrm{~B}, 1 \mathrm{C}, 1 \mathrm{D}, 1 \mathrm{E}$ and $1 \mathrm{~F}$, respectively). The Wilcoxon test showed that differences were significant when comparing the videos of the mom and the nanny, and those of the moon and the dinosaur. An increase on the LF:HR ratio was observed only to the video of the nanny, and Wilcoxon test pointed out a significant difference between this video and those of the mom and of the dinosaur. The Kruskal-Wallis test pointed out that no significant difference $(p>0.05)$ occurred in the cardiovascular responses in relation to the participants' gender.

\section{Relationships between Empathy, HRV and BP}

Data produced from the situational empathy scale (Sampaio et al., 2013) were firstly used to assess the most frequently and intensively experienced empathic feelings after the exposure of participants to the stimulus situations, as shown in Table 2.

As regards the empathy indicators obtained from the IRI, the Mann-Whitney Test pointed out significant differences related to sex, with women scoring higher than men at the empathy general level $(U=10 ; p=0.001)$, empathic concern $(\mathrm{U}=18 ; \mathrm{p}=0.009)$, personal distress $(\mathrm{U}=16 ; \mathrm{p}=0.006)$ and fantasy $(\mathrm{U}=22.5 \mathrm{p}=0.023)$ (Table 3$)$.

It was found significant and positive correlations between the empathy general level and the IRI subscales, as well as between the subdimensions of empathy measured by this instrument (Table 4). Moreover, the existence of correlation between empathic concern and intensity of sadness in the mom's video $(\rho=0.59 ; p=0.03)$ was also observed.

As regards the relationships between dispositional empathy and indicators of cardiovascular activity, Spearman Test pointed out the existence of significant correlations between perspective-taking and the DBP on the nanny's video, between HR and the LF:HF ratio in the mom's video with Perspective-Taking. Moreover, it was found a correlation between HR and RPP with personal distress in the nanny's video, HR in the mom's and in the moon's videos and fantasy, and finally, correlation between LF and HF and fantasy in the dinosaur's video. All the significant correlations involving dimensions of empathy and hemodynamic indicators are presented in Table 4. 

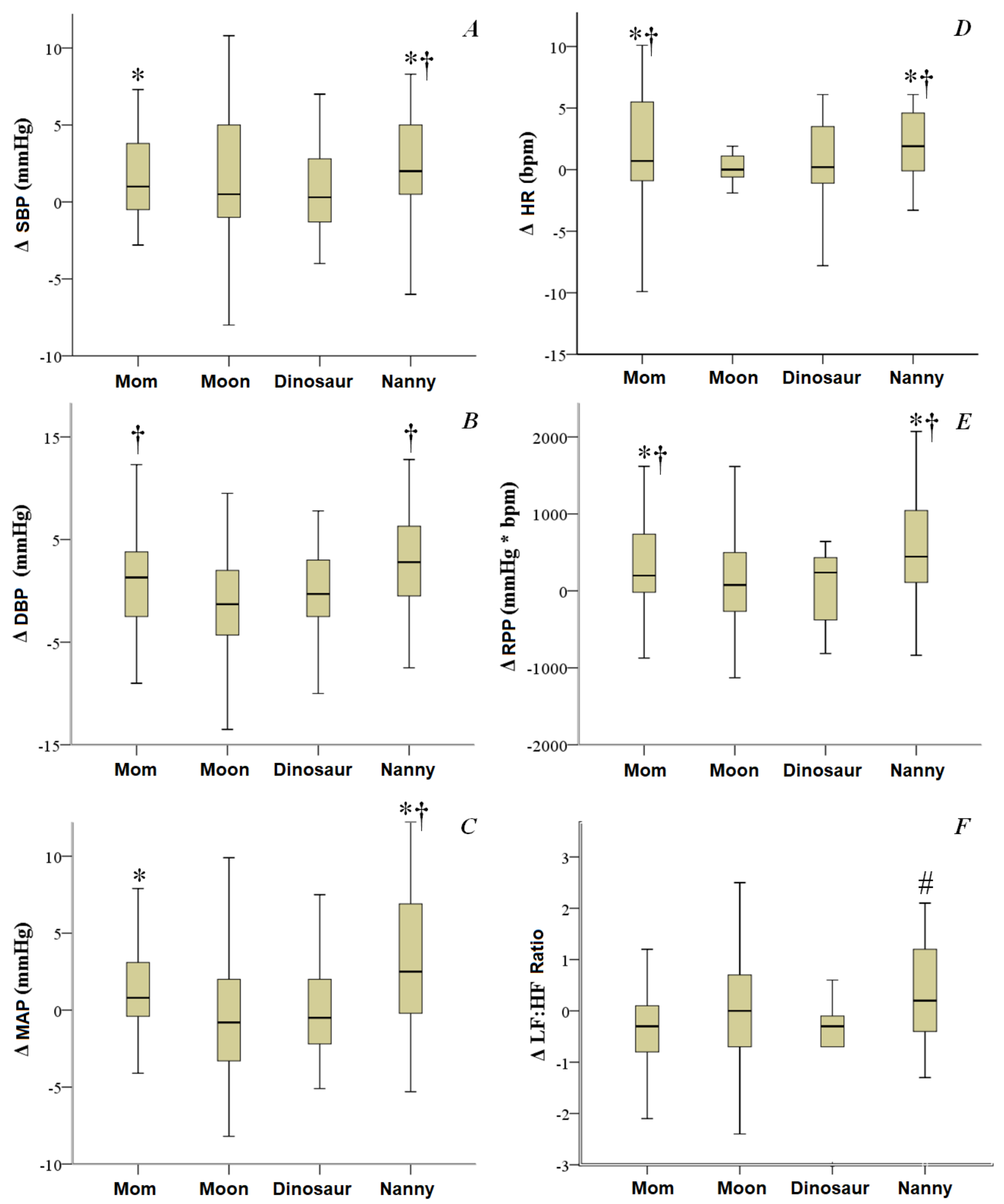

Figure 1. Hemodynamic and autonomic responses (results expressed as median), after the videos exhibition. (A) SBP = Systolic Blood Pressure; (B) $\mathrm{DBP}=$ Diastolic Blood Pressure; (C) MAP = Mean Arterial Pressure; (D) HR = Heart Rate; (E) RPP = Rate Product Pressure.* $\mathrm{p}<0,05$, comparing to Dinosaur; $\uparrow \mathrm{p}<0,05$, comparing to moon; \# $<<0,05$, comparing to Dinosaur and Mom. 
Table 2.

Frequency and intensity of the empathic feelings experienced after the exposure to the stimulus situations

\begin{tabular}{lccc}
\hline Feelings & Videos & \% & MEAN ( \pm SD) \\
\hline Sadness & Nanny & 52,4 & $3,73 \pm 1,19$ \\
Anger & Nanny & 81,0 & $3,41 \pm 0,79$ \\
Anguish & Mom & 57,1 & $3,58 \pm 0,90$ \\
Sadness & Mom & 61,9 & $3,46 \pm 0,87$ \\
Pride & Moon & 33,3 & $3,29 \pm 1,11$ \\
Happiness & Moon & 42,9 & $2,67 \pm 1,11$ \\
Pride & Dinosaur & 52,4 & $2,91 \pm 1,13$ \\
Happiness & Dinosaur & 42,9 & $2,78 \pm 1,48$ \\
\hline
\end{tabular}

Table 3.

Empathy and its dimensions by gender, expressed as mean ( \pm sd)

\begin{tabular}{lcccc}
\hline Empathy & Female & Male & F $_{(1,19)}$ & p \\
\hline General Level & $104,9 \pm 10,8$ & $81,6 \pm 15,9$ & 15,9 & 0,001 \\
Empathic Concern & $29,0 \pm 3,4$ & $22,7 \pm 5,5$ & 10,3 & 0,005 \\
Perspective-Taking & $25,0 \pm 3,1$ & $22,0 \pm 4,0$ & 3,6 & 0,07 \\
Personal Distress & $22,8 \pm 4,4$ & $16,0 \pm 4,8$ & 15,9 & 0,003 \\
Fantasy & $28,0 \pm 5,0$ & $20,8 \pm 6,7$ & 7,5 & 0,01 \\
\hline
\end{tabular}

Table 4.

Correlations between dispositional empathy and hemodinamic and autonomic indicators

\begin{tabular}{|c|c|c|c|c|c|}
\hline & 1 & 2 & 3 & 4 & 5 \\
\hline $\begin{array}{l}\text { Empathy General } \\
\text { Level (1) }\end{array}$ & - & - & - & - & - \\
\hline Empathic Concern (2) & $\begin{array}{l}\rho=0,84 \\
p<0,01\end{array}$ & - & - & - & - \\
\hline Perspective-Taking (3) & $\begin{array}{l}\rho=0,56 \\
p<0,01\end{array}$ & ns & - & - & - \\
\hline Personal Distress (4) & $\begin{array}{l}\rho=0,86 \\
p<0,01\end{array}$ & $\begin{array}{l}\rho=0,82 \\
p<0,01\end{array}$ & ns & - & - \\
\hline Fantasy (5) & $\begin{array}{l}\rho=0,76 \\
p<0,01\end{array}$ & $\begin{array}{l}\rho=0,51 \\
p=0,01\end{array}$ & ns & $\begin{array}{l}\rho=0,54 \\
p=0,01\end{array}$ & - \\
\hline$\Delta \mathrm{DBP}$ - Nanny & ns & ns & $\begin{array}{l}\rho=0,38 \\
p=0,04\end{array}$ & ns & ns \\
\hline$\Delta \mathrm{HR}-\mathrm{Mom}$ & ns & ns & $\begin{array}{l}\rho=0,37 \\
p=0,04\end{array}$ & ns & $\begin{array}{l}\rho=0,37 \\
p=0,05\end{array}$ \\
\hline$\Delta \mathrm{HR}$ - Nanny & ns & ns & ns & $\begin{array}{l}\rho=0,43 \\
p=0,02\end{array}$ & ns \\
\hline$\Delta \mathrm{RPP}$ - Nanny & ns & ns & ns & $\begin{array}{l}\rho=0,39 \\
p=0,04\end{array}$ & ns \\
\hline$\Delta \mathrm{HR}-$ Moon & ns & ns & ns & ns & $\begin{array}{l}\rho=0,37 \\
p=0,04\end{array}$ \\
\hline$\Delta \mathrm{LF}-$ Dinosaur & ns & ns & ns & ns & $\begin{array}{l}\rho=-0,39 \\
p=0,04\end{array}$ \\
\hline$\Delta \mathrm{HF}-$ Dinosaur & ns & ns & ns & ns & $\begin{array}{l}\rho=0,37 \\
p=0,05\end{array}$ \\
\hline$\Delta \mathrm{LF}: \mathrm{HF}$ ratio - Mom & ns & ns & $\begin{array}{l}\rho=0,40 \\
p=0,03\end{array}$ & ns & ns \\
\hline
\end{tabular}

* Note: $\triangle \mathrm{DBP}-$ Nanny $=$ variation of the Diastolic Blood Pressure, comparing baseline and the video of the Nanny; $\Delta \mathrm{HR}-\mathrm{Mom}=\mathrm{variation}$ of the Heart Rate, comparing baseline and the video of the Mom; $\Delta \mathrm{HR}$ - Nanny = variation of the Heart Rate, comparing baseline and the video of the Nanny; $\triangle \mathrm{RPP}-$ Nanny $=$ variation of the Rate Product Pressure, comparing baseline and the video of the Nanny; $\Delta \mathrm{HR}-$ Moon $=$ variation of the Heart Rate, comparing baseline and the video of the Mom; $\Delta \mathrm{LF}$ - Dinosaur = variation of the Low Frequency, comparing baseline and the video of the Dinosaur; $\Delta \mathrm{HF}-$ Dinosaur $=$ variation of the High Frequency, comparing baseline and the video of the Dinosaur; $\Delta \mathrm{LF}: \mathrm{HF}$ ratio - Mom $=$ variation of the LF:HF ratio, comparing baseline and the video of the Mom; 


\section{DISCUSSION}

The variations of SBP and DBP observed in relation to the videos watched suggest that empathy-related cardiovascular responses tend to be similar to those when the individual experiences self-referenced emotions. As observed in Figure 1, the two indicators have significantly increased when participants watched the mom's and the nanny's videos, more than when they were exposed to the videos of the moon and of the dinosaur. In the two first videos participants have reported anger and sadness more frequently and intensively.

This cardiovascular response pattern is similar to that observed in the studies by James et al. (1986) and Kreibig et al. (2007), in which anger and sadness were associated to significant increases of the SBP and DBP if compared to happiness, or the baseline. These results suggest that the autonomous nervous system tends to generate similar cardiovascular activity patterns, either when the individual faces stimuli that generate emotions, or when the individual only feels it in a vicarious way, resulting from empathy.

The correlation observed between the indicators of empathic concern and intensity of sadness, reported during the video of the mom that forgets the baby in the car, suggests that empathy trait components may influence more situational empathic responses. This would have led participants to take the perspective and have feelings congruent with those felt by the child's parents. This hypothesis is supported by Hoffman's theory (2000) that defines empathic concern as a feeling that mobilizes people to engage in actions to relieve the others' suffering, being directly related to the prosocial behavior.

Similarly to Fukushima's et al. (2011) work, this study also found significant relationships between dispositional empathy and cardiovascular and autonomic activity. More specifically, it was found that perspective-taking (PT) was associated to changes on BP and HR during exposure to the videos. Considering that this component of empathy corresponds to a cognitive capacity of putting the self in the others' shoes and to infer their internal states, it would be reasonable to infer that PT led participants to take on the perspective of the parents of the children described in the nanny's and the mom's videos. That mobilized the participants through anger, sadness and anguish (according to the evaluation in the dispositional empathy scale) leading to changes on their DBP, HR and LF:HR ratio, comparing to the baseline (Table 4).

However, one could challenge why these changes were not observed in relation to the SBP. Sinha et al. (1992) explain that during the feeling of anger the peripheral vascular resistance increases and, therefore, what is explained by important increases on the DBP, what does not happen with the SBP.
The correlations observed between personal distress (PD), RPP and HR during the nanny's news are in line with the PT-related results in that video and in the mom's video, suggesting that PD contributed to increase the participants' emotional involvement with this experimental situation. As PD corresponds to a type of empathic sensitivity experienced as discomfort by the self(Davis, 1983), when the individual faces the torment/anguish of the other, higher levels of that component made participants more prone to feel disturbed and distressed with the suffering of the beaten child and her parents. This may have been reflected in autonomic and hemodynamic activation patterns, typical to the states of anxiety/concern in which the HR increases (Stein et al, 1992).

Another result found refers to the correlations between $\mathrm{HR}$ and the LF and HF and fantasy components in the videos of the moon and of the dinosaur, as these were equally selected for their low potential of generating empathic feelings in participants in comparison with the nanny's and the mom's videos. However, the results suggest that exposure to these videos mobilized cognitive components of empathy, which was reflected in hemodynamic and autonomic responses that could be detected during the experiment. For the video on the discovery of water in the moon, fantasy could have facilitated the participants' identification with the authors of the discovery, or even with the kind of activity shown in the news (scientific discovery), so that the more fantasy, higher the possibility of the person imagining him/herself making a discovery as important as that one someday in his/her life, and vice-versa.

In this sense, it is worth recalling that all participants were university students and during their academic training they are stimulated to improve their technical-scientific skills so they can contribute to science advance in the future, a reason for pride and joy. This explanatory hypothesis is reinforced when we observe the systematic variations in $\mathrm{HR}$, and also the greater frequency of happiness reported in this video, moreover when we consider previous studies that found a relationship among motivation, happiness and variations in the HR (Uchiyama, 1992; Vrana \& Gross, 2004).

As regards the autonomic adjustments observed in the LF and HF indicators during exposure to the news on dinosaur and its correlations with fantasy, it suggests that this component of empathy contributed to the lesser activation of the sympathetic modulation (LF) and, consequently, to the increase on the parasympathetic modulation (HF). This supports the findings of Hughes and Hutt (1979) that found a higher HRV in children that imagined "something they liked". In other words, the higher levels of fantasy contributed to the lower level of affective-cognitive mobilization and more 
relaxation in this situation. This would support the initial idea that this video was expected to generate lower level of affective mobilization in participants. We would suggest that further studies deepen this comparison among the stimulus situations, as well as the level of familiarity with the stimulus by comparing, for example, people with different levels of engagement in the academic-scientific life.

It is worth noticing that, despite the significant correlations between self-reported and physiological measures of empathy, some results may seem even contradictory, as it happens with the sex differences observed in the IRI measures, but not found in the BP and HRV measures. An explanation to that rests on the criticism of Eisenberg et al. (1987) to the self-reported measures as these are very susceptible to social desirability. Other studies (Sampaio et al., 2013) have raised questions in this sense, suggesting that the tendency of finding higher scores among women in the self-assessed scales of empathy would ensue from the search for acceptance and compliance with the male and female social roles found in our society.

Therefore, by answering a self-report instrument women would tend to perceive and assess themselves as more careful and compassionate (behaviors associated to empathy) than men that, in turn, would perceive themselves as less emotionally sensitive, which could be reflected in higher empathy scores to women. On the other hand, the cardiovascular responses, less susceptible to the conscious control of the individuals, would better reflect the actual level of affective excitability when exposed situations that could generate empathy.

Hence, the results found in this study suggest that men and women may even recognize and describe themselves as different in terms of empathic responsiveness. However, the hemodynamic and autonomic cardiovascular adjustments follow quite similar patterns, in order to not reflect these differences subjectively perceived by people. This is in line with the results observed by Chaplin, Hong, Bergquist and Sinha (2008). Further studies could better investigate this assumption, based on the expanded use of methods that combine psychophysiological and behavioral measures.

One of the limitations in this study could be related to the use of movies as experimental stimulus, because they tend to generate different patterns of affective excitement, including of feelings/emotions that are not original objects of experimental manipulation. For this reason, some authors advocate for the use of videos only in situations in which they have already been validated, in order to enhance the control of their effects on emotional excitement (Kreibig et al, 2007).

On the other hand, the use of TV news allowed a more naturalistic approach of the situational empathy, since exposure to this kind of media is very usual and is part of the adults' everyday life in our society. This is reflected in an enhancement of the external validity of the study. In fact, we should consider that TV news is one of the main sources of access to information available these days. Moreover, the use of news would allow participants to access information about the reasons for and consequences of actions performed by the people involved. To Hoffman (2000) this is an important element to the empathic excitement in adult life.

In this sense, this methodological approach is considered to represent an advance in relation to studies that use static images or short vignettes that show emotional expressions out of a real context. Even so, the effects of different methods of induction of psychophysiological responses related to empathy should be better discussed and systematically compared in future studies.

Another issue that should be considered refers to a potential cumulative effect of affective experiences resulting from exposure to the four videos on the cardiovascular activity. It means to say that, when watching the last video, the cardiac indicators are already reflecting the emotional consequences of exposure as a whole, rather than only of affections generated by one video. Therefore, it would be important to include some methodological procedure to test the existence of this sort of cumulative effect through the comparison between experimental conditions with the inclusion of a new rest period between the videos exhibition, what would allow building a sort of secondary baseline.

Moreover, previous studies show that physical activity has a direct impact on the HRV modulation (Moreira, Teixeira-Araujo, Oliveira dos Santos \& Simões, 2016). This suggests that regular engagement with physical activities works as a protective factor to the cardiovascular system (Ribeiro et al., 2011). For this reason, the level of physical activity should be better controlled in the samples investigated in future studies, to prevent a possible bias on the cardiac autonomic response to situations of emotional stress. In addition, the adoption of such control would also allow assessing if the effects of physical activity also affect somehow the subjective experience of empathy.

Finally, we should consider the importance of comparing the HRV indicators when affects are vicarious (empathically felt) and situations of autobiographical recalling, what could affect the assessment of the magnitude of sympathovagal activation in both situations. The proposal would be to assess if the individuals' cardiovascular system responds in the same magnitude when feelings are self-referenced or when they are produced from vicarious experience of empathy. This would allow better understanding, based on the cardiovascular system activity, to which extent empathy effectively is in relation to the others' feelings (Hoffman, 2000). 


\section{REFERENCES}

Chaplin, T.M., Hong, K., Bergquist, K., \& Sinha, R. (2008). Gender differences in response to emotional stress: An assessment across subjective, behavioral, and physiological domains and relations to alcohol craving. Alcoholism Clinical and Experimental Research, 32(7), 1242-1250. doi:10.1111/j.15300277.2008.00679.x

Dantas, E.M., Gonçalves, C.P., Silva, A.B.T., Rodrigues, S.L., Ramos, M.S., Andreão, R.V., ... Mill, J.G. (2010). Reproducibility of heart rate variability parameters measured in healthy subjects at rest and after a postural change maneuver. Brazilian Journal of Medical and Biological Research, 43(10), 982-988. doi:10.1590/S0100-879X2010007500101

Davis, M. H. (1983). Measuring individual differences in empathy: Evidence for a multidimensional approach. Journal of Personality and Social Psychology, 44(1), 113-136. doi:10.1037/0022-3514.44.1.113

Eisenberg, N., Fabes, R. A., Bustamante, D., \& Mathy, R. M. (1987). Physiological indices of empathy. In N. Eisenberg \& J. Strayer (Orgs.), Empathy and its development (pp.380-385). Cambridge University Press: New York.

Ekman, P., Levenson, R. W., \& Friesen, W. (1983). Autonomic Nervous System Activity distinguishs among emotions. Science, New Series, 221(4616), 1208-1210.

Ewing, D. J., Neilson, J. M., Shapiro, C. M., Stewart, J. A., \& Reid, W. (1991). Twenty four hour heart rate variability: Effects of posture, sleep, and time of day in healthy controls and comparison with bedside tests of autonomic function in diabetic patients. BMJ Heart, 65, 239-244. doi:10.1136/hrt.65.5.239

Freydefont, L., Gendolla, G.H.E., \& Silvestrini, N. (2012). Beyond valence: The differential effect of masked anger and sadness stimuli on effort-related cardiac response. Pshychophysiology, 49, 665-671. doi:10.1111/j.1469-8986.2011.01340.x

Fuskushima, H., Terasawa, Y., \& Umeda, S. (2011). Association between interoception and empathy: Evidence from heartbeat-evoked brain potential. International Journal of Psychophysiology, 79, 259-265. doi:10.1016/j. ijpsycho.2010.10.015

Gendolla, G. H. E. (2012). Implicit affect primes effort: A theory and research on cardiovascular response. International Journal of Psychophysiology, 86, 123-135. doi:10.1016/j. ijpsycho.2012.05.003

Hoffman, M. L. (2000). Empathy and moral development: Implications for caring and justice. Cambridge University Press.

Hughes, M., \& Hutt, C. (1979). Heart-rate correlates of childhood activities: play, exploration, problem.solving and daydreaming. Biological Psychology, 8, 53-263. doi:10.1016/03010511(79)90007-3

Jackson, A.S., \& Pollock, M. L. (1978). Generalized equations for predicting body density of men. British Journal of Nutrition, 40(3), 497-504. doi:10.1079/BJN19780152

Jackson, A.S., Pollock, M.L., \& Ward, A. (1980). Generalized equations for predicting body density of women. Medicine \& Science in Sports \& Exercise, 12(3), 175-81. doi:10.1249/00005768-198023000-00009

James, G. D., Yee, L. S., Harshfield, G. A., Blank, S. G., \& Pickering, T. G. (1986). The influence of happiness, anger, and anxiety on the blood pressure of borderline hypertensives. Psychosomatic Medicine, 48(7), 502-8. doi:10.1097/00006842-19860900000005

Kenney, W. L., Wilmore, J. H., \& Costill, D. L. (2013). Fisiologia do esporte e do exercício ( $5^{\mathrm{a}}$ ed.). Barueri, SP: Manole.

Kreibig, S. D., Wilhelm, F. H., Roth, W., \& Gross, J. J. (2007). Cardiovascular, electrodermal, and respiratory response patterns to fear- and sadness-inducing films. Psychophisiology, 44, 787-806. doi:10.1111/j.14698986.2007.00550.x

Lipp, M. E., Pereira, M. M., Justo, A. P., \& De Matos, T. M. (2006). Cardiovascular reactivity in hypertensives: differential effect of expressing and inhibiting emotions during moments of interpersonal stress. The Spaninsh Journal of Psychologu, 9(2), 154-161. doi:10.1017/S1138741600006053

Lohman, T.G., Roche, A.F., \& Martorell, R. (1988). Anthropometric standardization reference manual. Champaign, Illinois: Human Kinetics Books.

Moreira, S. R., Teixeira-Araujo, A. A., Oliveira dos Santos, A., \& Simões, H. G. (2016). Ten weeks of capoeira progressive training improved cardiovascular parameters in male practitioners. The Journal of Sports Medicine and Physical Fitness. [Epub ahead of print]. doi: 10.23736/S00224707.16.06030-8

Oliveira-Gonçalves, P., \& Gonçalves, O.F. (2011). Responding empathically: A question of heart, not a question of skin. Applied Psychophysiological Biofeedback, 36, 201-207.

Pinna, G.D., Maestri, R., Torunski, A., Danilowicz-Szymanowicz, L., Szwoch, M., La Rovere, M.T., \& Raczak, G. (2007). Heart rate variability measures: A fresh look at reliability. Clinical Science, 113, 131-140. doi:10.1042/CS20070055

Preston, S. D., \& De Waal, F. M. M. (2002). Empathy: Its ultimate and proximate bases. Behavioral and Brain Sciences, 25, 1-72. doi:10.1017/S0140525X02000018

Prkachin, K. M., Williams-Avery, R. M., Zwaal, C., \& Mills, D. E. (1999). Cardiovascular changes during induced emotion: an application of Lang's theory of emotional imagery. Journal of Psychosomatic Research 47(3), 255-267, http://dx.doi. org/10.1016/S0022-3999(99)00036-7

Queiroz, A.C.C., Kanegusuku, H., Chehuen, M.R., Costa, L.A.R., Wallerstein, L.F., Silva, V.J.D., ... Forjaz, C.L.M. (2013). Cardiac work remains high after strength exercise in elderly. International Journal of Sports Medicine, 34(5), e2. doi:10.1055/s-0032-1331707

Rainville, P., Bechara, A., Naqvi, N., \& Damasio, A. R. (2006). Basic emotions are associated with distinct patterns of cardiorespiratory activity. International Journal of Psychophysiology, 61, 5-18. doi:10.1016/j.ijpsycho.2005.10.024

Ribeiro, F., Campbell, C.S.G., Mendes, G., Arsa, G., Moreira, S.R., \& Silva, F.M. (2011). Exercise lowers blood pressure in university professors during subsequent teaching and sleeping hours. Internation Journal of General Medicine, 4, 711-716.

Sampaio, L. R., Guimarães, P. R. B., Camino, C. P. D. S., Formiga, N. S., \& Menezes, I. G. (2011). Estudos sobre a dimensionalidade da empatia: Tradução e adaptação do Interpersonal Reactivity Index (IRI). Psico, 42(1), 67-76.

Sampaio, L. R., Moura, A. R., Guimarães, P. R. B., Santana, L. B., \& Camino, C. P. S. (2013). Sentimentos empáticos em crianças adolescentes e adultos. Psicologia: Teoria e Pesquisa, 29(4), 393-401.

Singh, R.; Singh, R. K.; Mahdi, A.A.; Misra, S.; Rai, S.P.; Singh, D.; Cornélissen, G. \& Halberg, F. (1998). Studies on circadian periodicity of urinary corticoids in carcinoma of breast. In Vivo (Athens, Greece), 12, 69-73.

Sinha, R., Lovallo, W. R., \& Parsons, O. A. (1992). Cardiovascular differentiation of emotions. Psychosomatic Medicine, 54, 422435. doi:10.1097/00006842-199207000-00005

Sociedade Brasileira de Cardiologia. (2010). VI Diretrizes Brasileiras de Hipertensão. Arquivos Brasileiros de Cardiologia, 95(1), suppl.1, 1-51 
Stein, J. M., Papp, L. A., Klein, D. F., Cohen, S., Simon, J., \& Ross, D. (1992). Exercise tolerance in panic disorder patients. Biological Psychiatry, 32, 281-287. doi.:10.1016/00063223(92)90109-D

Task Force of The European Society of Cardiology and The North American Society of Pacing and Electrophysiology. (1996). Heart rate variability Standards of measurement, physiological interpretation, and clinical use. European Heart Journal, 17, 354-381.

Topouchian, J. A., El Assaad, M. A., Orobinskaia, L. V., EL Feghali, R. N., \& Asmar, R. G. (2005). Validation of two devices for self-measurement of brachial blood pressure according to the International Protocol of the European Society of Hypertension: the SEINEX SE-9400 and the Microlife BP 3AC1-1. Blood Pressure Monitoring, 10(6), 325-331. doi:10.1097/00126097200512000-00008

Tulppo, M. P., Mäkikallio, T. H., Seppänen, T., Airaksinen, J. K., \& Huikuri, H. V. (1998). Heart rate dynamics during accentuated sympathovagal interaction. American Journal of Physiology, 274(3), 810-816

Uchiyama, I. (1992). Differentiation of fear, anger and joy. Perceptual and Motor Skills, 74, 663-667. doi:10.2466/ pms.1992.74.2.663

Vanderlei, L. C. M., Pastre, C. M., Hoshi, R. A., Carvalho, T. D., \& Godoy, M. F. (2009). Basic notions of heart rate variability and its clinical applicability. Revista Brasileira de Cirurgia Cardiovascular, 24(2), 205-217.

Vrana, S. R., \& Gross, D. (2004). Reactions to facial expressions: effects of social context and speech anxiety on responses to neutral, anger, and joy expressions. Biological Psychology, 66, 63-78. doi:10.1016/j.biopsycho.2003.07.004

Williams, D. P., Jarczok, M. N., Ellis, R. J., Hillecke, T. K., Thayer, J. F., \& Koenig, J. (2016). Two-week test-retest reliability of the Polar ${ }^{\circledR}$ RS800CX ${ }^{\mathrm{TM}}$ to record heart rate variability. Clinical Physiology and Functional Imaging, 27. doi: 10.1111/ cpf. 12321 